Sharif University of Technology
Scientia Iranica
Transactions B: Mechanical Engineering
http://scientiairanica.sharif.edu
SCIENTIA

\title{
The response of nano-ceramic doped fluids in heat convection models: A characteristic-based numerical approach
}

\author{
T. Adibi ${ }^{a, *}$, S.E. Razavi ${ }^{b}$, O. Adibi ${ }^{c}$, M. Vajdi ${ }^{d}$, and F. Sadegh Moghanlou ${ }^{\text {d }}$ \\ a. Department of Mechanical Engineering, University of Bonab, Bonab, P.O. Box 5551761167, Iran. \\ b. School of Mechanical Engineering, University of Tabriz, Tabriz, P.O. Box 5166616471, Iran. \\ c. Energy Management Group, Energy and Environment Research Center, Niroo Research Institute, Tehran, P.O. Box 1468613113, \\ Iran. \\ d. Department of Mechanical Engineering, University of Mohaghegh Ardabili, Ardabil, P.O. Box 56199-11367, Iran.
}

Received 8 August 2020; received in revised form 14 November 2020; accepted 18 January 2021

\begin{abstract}
KEYWORDS
Nano-fluid;

Mixed convection;

Cavity;

Flow over a cylinder;

Richardson number.
\end{abstract}

\begin{abstract}
In this paper, forced, free, and mixed convections in incompressible flow were studied numerically. Nano-sized $\mathrm{Al}_{2} \mathrm{O}_{3}, \mathrm{TiO}_{2}, \mathrm{MgO}$, and $\mathrm{ZnO}$ ceramics with water were considered as nano-fluids. This study simulated a cavity flow with different boundary conditions and aspect ratios as well as flow over stationary and rotating cylinders. The mean Nusselt number $(\overline{\mathrm{Nu}})$ and friction factor for cavity flow and $(\overline{\mathrm{Nu}})$ for flow over a cylinder were compared for different nano-fluids. A new code was developed in FORTRAN 95 for numerical simulations. A fifth-order Runge-Kutta method for time discretization and a characteristic-based scheme for convective terms were used in this code. The averaging scheme on the secondary cells was employed to obtain viscous fluxes. Primary results were validated in comparison to other research outputs. Results demonstrated that $\mathrm{MgO}$-water and $\mathrm{ZnO}$-water had maximum and minimum heat transfer rates, respectively. Moreover, maximum and minimum shear stresses were recorded for the $\mathrm{Al}_{2} \mathrm{O}_{3}$-water and $\mathrm{TiO}_{2}$-water, respectively. Using nano-fluid increased the heat transfer rate by $15-37 \%$, depending on the Richardson number and selected nano-particles.
\end{abstract}

(C) 2021 Sharif University of Technology. All rights reserved.

\section{Introduction}

Optimization of thermal systems and use of renewable energy sources are the inevitable ways of attenuating the threat and intensity of air pollution, global warming, and environmental concerns as well as de-

\footnotetext{
*. Corresponding authors.

E-mail addresses: tohidadibi@ubonab.ac.ir (T. Adibi); razavi@tabrizu.ac.ir (S.E.Razavi); oadibi@nri.ac.ir (O. Adibi); F_moghanlou@sut.ac.ir (F. Sadegh Moghanlou)
}

doi: $10.24200 /$ sci. 2021.56574 .4794 creasing other related costs. Enhancement of heat transfer in thermal systems is the basic part of system optimization. There are two major categories of heat transfer enhancement: active and passive methods [1]. In active methods, some types of external energies including electric field, magnetic field, and acoustic force are employed to perturb the fluid flow and increase the heat transfer rate, whereas, in passive methods, the enhancement is achieved by making changes to the geometrical configuration of the system or manipulating the working fluid [2]. Nano-fluids, as newborn working fluids, belong to the group of passive methods. The term nano-fluids refer to stable 
dispersion of nano-sized particles in a base fluid. Solid materials generally possess high thermal conductivities than conventional fluids; therefore, the addition of solid particles improves their thermal properties [3]. The interesting properties of nano-fluids are the reasons behind the researchers' and engineers' motivation to investigate their application in various fields of engineering including Micro Electro-Mechanical Systems (MEMS), fuel cells, and heat treatment of metals [4]. Still, a wide range of experimental works are needed to provide a reliable database to establish a comprehensive theory about nano-fluids. Conducting accurate experimental researches is costly and timeconsuming. Moreover, working with nanoparticles is subject to its particular dangers about the safety of the experimenter. On the other hand, extracting accurate data is difficult and sometimes impossible, e.g., determining the temperature of each point in micro-channels. Uncertainties related to measuring instruments and sources of error including instrumental, environmental, procedural, and human are the other drawbacks of using experimental methods. Numerical methods, however, represent a powerful tool for analyzing almost all physical phenomena and they can provide detailed information concerning each desired location.

Maiga et al. [5] managed to study the effect of $\mathrm{Al}_{2} \mathrm{O}_{3}$ dispersion in two different media, water and ethylene glycol. They investigated the forced convection of the mentioned nano-fluid numerically and reported that using alumina nanoparticles enhanced the heat transfer of both fluids. They found that the ethylene glycol- $\mathrm{Al}_{2} \mathrm{O}_{3}$ combination achieved better heat transfer enhancement than water- $\mathrm{Al}_{2} \mathrm{O}_{3}$. However, wall shear stress was higher at the same time. Kefayati [6] studied natural convection flow with $\mathrm{Cu}$-water nano-fluid by the Lattice-Boltzmann scheme in a cavity at different Aspect Ratios (ARs). The magnetic field was applied in the flow domain. The results demonstrated that the effect of the nanoparticles increased at large Hartmann numbers as the AR increased. Mahmoodi [7] studied the effect of particle type on natural convection of the cavity flow with different heaters in it. They employed the water as a base fluid and performed a series of numerical simulations using the SIMPLER algorithm. Their results demonstrated that a horizontally located heater would have a higher $\mathrm{Nu}$ value at small $\mathrm{Ra}$ numbers than a perpendicularly placed heater, but the location of the radiator did not affect $\mathrm{Nu}$ at large Ra numbers. Rahmati and Tahery [8] simulated the laminar natural convection in a cavity using $\mathrm{TiO}_{2}$-water nano-fluid. They proposed some obstacles in the base geometry and used the Lattice-Boltzmann method to predict the velocity field and thermal behavior of the nano-fluid. They found that the $(\overline{\mathrm{Nu}})$ value increased upon an increase in Rayleigh number and the volume fraction of nanoparticles. They also reported that the obstacle dimension had a direct effect on the thermal behavior of the cavity such that the $(\overline{\mathrm{Nu}})$ improved despite the obstacle dimensions up to $0.5 \mathrm{~L}$; however, the Nusselt number deteriorated as the obstacle dimensions increased to $0.7 \mathrm{~L}$.

Akbarinia and Behzadmehr [9] studied numerically the mixed convection of $\mathrm{Al}_{2} \mathrm{O}_{3}$-water nano-fluid within a tube. Their results illustrated that the concentration of nanoparticles had no direct effect on the secondary flow, axial velocity, and friction coefficient. They claimed that the rising volume fraction of nanoparticles increased $\mathrm{Nu}$ and reduced friction factor (f). Heydari et al. [10] simulated the three-dimensional nano-fluid flow in a heat exchanger. They used $\mathrm{SiO}_{2}, \mathrm{CuO}, \mathrm{Au}, \mathrm{Cu}, \mathrm{Fe}, \mathrm{Al}_{2} \mathrm{O}_{3}$, and $\mathrm{Fe}_{2} \mathrm{O}_{3}$ in ethylene glycol and water-based fluids. It was reported that the ethylene glycol-based nano-fluids had higher efficiencies. Uysal et al. [11] performed a threedimensional simulation in a circular tube using $\mathrm{ZnO}-$ ethylene glycol nano-fluid. Their results showed $10 \%$ enhancement of Nusselt number in a concentration of 1\%. Sunil and Kumar [12] used the Lattice-Boltzmann scheme to simulate the $\mathrm{Al}_{2} \mathrm{O}_{3}$-water nano-fluid. They found that increase in the heat transfer rate was not dependent on Reynolds number variation. Al-Kouz et al. [13] two-dimensionally simulated the cavity using $\mathrm{Al}_{2} \mathrm{O}_{3}-\mathrm{Air}$ nano-fluid and employed two fins on the hot wall to increase the effect of nano-fluid on the rising Nusselt number. Natural laminar convection flow was considered in this work and Knudsen number ranged between 0 and 0.1 , while the Rayleigh number ranged between $10^{3}$ and $10^{6}$. They found that $\mathrm{Nu}$ was a function of Rayleigh number and inverse of Knudsen number. They proposed a new relation for the Nusselt number as $\mathrm{Nu}=0.219 \mathrm{Ra}^{0.0829} \mathrm{Kn}^{-0.511} \phi^{0.104}$.

Zhang et al. [14] conducted a numerical study to simulate nano-fluid flow and employed an adaptive grid method to ensure accuracy. Using industrial nanofluid to improve heat transfer rate has increased in recent years. The numerical method costs less than experimental methods. Hence, numerical methods are excellent for gaining an initial understanding of nanofluid flow behavior. As a result, different numerical studies of nano-fluid flow have been done so far [1518]. The literature review points to the valuable scope of numerical simulations performed to predict the behavior of nano-fluids. However, the unknown nature of the involved mechanisms is still a big challenge to completely cover the thermal behavior of these fluids such that in some cases, the numerical simulations are considerably distant from, or inconsistent with, the experimental data. Therefore, it is required to examine different schemes to reduce the related numerical errors. The present work aims to solve the governing 
equations of the nano-fluids using the characteristicbased scheme proposed previously by our group [1921]. To investigate the potential of the present scheme, four types of nanoparticles including $\mathrm{Al}_{2} \mathrm{O}_{3}, \mathrm{TiO}_{2}$, $\mathrm{MgO}$, and $\mathrm{ZnO}$ ceramics in base water are considered. Different types of convections are simulated numerically for nano-fluids and a pure fluid. The present scheme is applied to two different geometries: cavity flow and flow over a cylinder. The cavity flow is simulated at different ARs, boundary conditions, and Richardson numbers. The flow over the cylinder is simulated in two cases of stationary and rotating cylinders.

\section{The governing equations and the numerical procedure}

Nano-fluids can be considered as single-phase fluids in numerical studies in which their physical characteristics depend on the characteristics of the base fluid and the nanoparticles. The following are Navier-Stokes equations for a two-dimensional nano-fluid with heat transfer:

$$
\begin{aligned}
& \frac{\partial u}{\partial x}+\frac{\partial v}{\partial y}=0 \\
& \frac{\partial u}{\partial t}+u \frac{\partial u}{\partial x}+v \frac{\partial u}{\partial y}=-\frac{1}{\rho} \frac{\partial p}{\partial x}+v\left(\frac{\partial^{2} u}{\partial x^{2}}+\frac{\partial^{2} u}{\partial y^{2}}\right) \\
& \frac{\partial v}{\partial t}+u \frac{\partial v}{\partial x}+v \frac{\partial v}{\partial y}=-g-\frac{1}{\rho} \frac{\partial p}{\partial y}+v\left(\frac{\partial^{2} v}{\partial x^{2}}+\frac{\partial^{2} v}{\partial y^{2}}\right) \\
& \frac{\partial T}{\partial t}+u \frac{\partial T}{\partial x}+v \frac{\partial T}{\partial y}=\frac{1}{\rho C_{p}}\left(u \frac{\partial p}{\partial x}+v \frac{\partial p}{\partial y}\right) \\
& +\frac{k}{\rho C_{p}}\left(\frac{\partial^{2} T}{\partial x^{2}}+\frac{\partial^{2} T}{\partial y^{2}}\right)+\frac{\mu}{\rho C_{p}} \Phi \\
& \Phi=\left(\frac{\partial u}{\partial y}+\frac{\partial v}{\partial x}\right)^{2}+2\left(\left(\frac{\partial u}{\partial x}\right)^{2}+\left(\frac{\partial v}{\partial y}\right)^{2}\right) .
\end{aligned}
$$

The artificial compressibility of Chorin [22] is applied and the gradient of pressure is added to the continuity equation. As a result, the pressure can be obtained by numerical schemes. Also, the nature of governing equations varies and the characteristicbased scheme proposed by ourselves can be used as a numerical scheme. This scheme solves the problems of the averaging scheme [19-21]. The instability of the averaging scheme is a serious problem solved by using our proposed characteristic-based scheme.

$$
\frac{1}{\varepsilon} \frac{\partial p}{\partial t}+\frac{\partial u}{\partial x}+\frac{\partial v}{\partial y}=0
$$

where $\varepsilon$ is the artificial compressibility factor [22]. The governing equations can be transformed into dimensionless forms and shown in the matrix shape as follows:

$$
\begin{aligned}
& \frac{\partial Q}{\partial t}+\frac{\partial F}{\partial x}+\frac{\partial G}{\partial y}=\frac{\partial R}{\partial x}+\frac{\partial S}{\partial y}+H \\
& Z=\left[\begin{array}{c}
p \\
u \\
v \\
T
\end{array}\right], \quad F=\left[\begin{array}{c}
\beta u \\
p+u^{2} \\
u v \\
(T-E c p) u
\end{array}\right], \\
& G=\left[\begin{array}{c}
\beta v \\
u v \\
p+v^{2} \\
(T-E c p) v
\end{array}\right], \quad R=\frac{1}{\operatorname{Re}}\left[\begin{array}{c}
0 \\
\frac{\partial u}{\partial x} \\
\frac{\partial v}{\partial x} \\
\frac{1}{\operatorname{Pr}} \frac{\partial T}{\partial x}
\end{array}\right], \\
& S=\frac{1}{\operatorname{Re}}\left[\begin{array}{c}
0 \\
\frac{\partial u}{\partial y} \\
\frac{\partial v}{\partial y} \\
\frac{1}{\operatorname{Pr}} \frac{\partial T}{\partial y}
\end{array}\right], \quad H=\left[\begin{array}{c}
0 \\
\frac{G r}{\operatorname{Re}} T \\
\frac{E c}{\operatorname{Re}} \Phi
\end{array}\right] \\
& \Phi=\left(\begin{array}{c}
\left.\frac{\partial u}{\partial y}+\frac{\partial v}{\partial x}\right)^{2}+2\left(\left(\frac{\partial u}{\partial x}\right)^{2}+\left(\frac{\partial v}{\partial y}\right)^{2}\right. \\
+
\end{array}\right) .
\end{aligned}
$$

Dimensionless parameters are defined as follows:

$$
\begin{aligned}
& \operatorname{Re}=\frac{\rho_{r e f} u_{r e f} L_{r e f}}{\mu}, \quad \operatorname{Pr}=\frac{c_{P} \mu}{k}, \\
& E c=\frac{u_{r e f}^{2}}{c_{P}\left(T_{r e f 2}-T_{r e f 1}\right)}, \\
& \mathrm{Gr}=\frac{\beta_{e x} g\left(T_{r e f 2}-T_{r e f 1}\right) L_{r e f}^{3}}{v^{2}}, \quad \operatorname{Ri}=\frac{G r}{\operatorname{Re}^{2}} .
\end{aligned}
$$

The reference length for a cavity flow is equal to the width of the cavity and for the flow over a cylinder is the diameter of the cylinder. The reference velocity and density are the far-field velocity and density, respectively. The Mach number of the flow is less than 0.3 ; hence, the flow is considered incompressible flow, but the Boussinesq assumption is applied to ensure density change in the $y$-direction because of the temperature gradient in the flow field. Reference temperatures include the temperatures of warm and cold walls for cavity as well as the far-field and wall of the cylinder for flow over the cylinder. The properties of water, nanoparticles, and nano-fluids are extracted from Ref. [23]. The following equations are used in the case of nano-fluids in order to determine their thermodynamic characteristics [24]:

$$
\begin{aligned}
& \frac{\rho_{n f}}{\rho_{b f}}=1-C+C \frac{\rho_{p}}{\rho_{b f}}, \quad \frac{\mu_{n f}}{\mu_{b f}}=1+C N v, \\
& \frac{\left(\rho C_{p}\right)_{n f}}{\left(\rho C_{p}\right)_{b f}}=1-C+C \frac{\left(\rho C_{p}\right)_{p}}{\left(\rho C_{p}\right)_{b f}}, \quad \frac{k_{n f}}{k_{b f}}=1+C N c,
\end{aligned}
$$




$$
\frac{\beta_{n f}}{\beta_{b f}}=\frac{\rho_{n f}}{\rho_{b f}}\left[(1-C)+C \frac{(\rho \beta)_{p}}{(\rho \beta)_{b f}}\right] .
$$

The governing equations are discretized by the FVM, where the fifth-order Runge-Kutta is used for time discretization as follows:

$$
\begin{aligned}
& Z_{i j k}^{(q)}=Z_{i j k}^{(n)}-F\left(\mathrm{Z}_{i j k}^{(q-1)}\right), \\
& \alpha_{q}=\frac{1}{4}, \frac{1}{6}, \frac{3}{8}, \frac{1}{2}, 1, \quad q=1,2, \ldots, 5 .
\end{aligned}
$$

The time step is considered $10^{-4}$ for a stable solution. The usual upwind scheme can be used for time discretization, but the Runge-Kutta method is much more stable $[25,26]$. The convective fluxes are calculated through our proposed characteristicbased scheme [20,21]. The first-order derivatives (convective fluxes) in cell centers are changed into normal parameters on cell boundaries based on Green's theorem. The averaging method is a simple method for calculating the convective fluxes. In this respect, the convective fluxes are obtained through simple averaging of cell center data. However, this method is not stable and this is the reason why it is replaced by the characteristic-based method introduced by the authors. The introduced scheme is stable. The pseudo wave propagation is considered in this method and convective fluxes are calculated by the pseudo waves. This scheme was elaborated in detail in [20,21]. The viscous fluxes (the second-order derivatives) in the cell center are replaced by the first-order derivatives on the cell boundaries. Obtained first-order derivatives are replaced by normal parameters on the boundaries of secondary cells based on Green's theorem (Eq. (7)).

$$
\begin{aligned}
\left.\frac{\partial \xi}{\partial x}\right|_{A B} & =\frac{1}{A} \iint_{A} \frac{\partial \zeta}{\partial x} d s=\frac{1}{A} \oint \zeta d y=\frac{1}{A} \sum_{k=1}^{4} \xi \Delta y_{k}, \\
\zeta & =u, v, T,
\end{aligned}
$$

where $f$ and $\mathrm{Nu}$ are calculated as follows:

$$
\begin{aligned}
& f=\frac{2}{\operatorname{Re}} \frac{\mu_{n f}}{\mu_{b f}} \frac{\partial u}{\partial y}=\frac{2}{\operatorname{Re}} \frac{\mu_{n f}}{\mu_{b f}} \frac{u_{2}-u_{1}}{y_{2}-y_{1}}, \\
& \mathrm{Nu}=\frac{2}{\operatorname{Re}} \frac{k_{n f}}{k_{b f}} \frac{\partial T}{\partial y}=\frac{2}{\operatorname{Re}} \frac{k_{n f}}{k_{b f}} \frac{T_{2}-T_{1}}{y_{2}-y_{1}} .
\end{aligned}
$$

Also, $\bar{f}$ and $(\overline{\mathrm{Nu}})$ for cavity flow are obtained through the following equations:

$$
\begin{aligned}
& \bar{f}=\int_{0}^{1} f d x=\frac{1}{N} \sum_{j=1}^{N} f_{j}, \\
& \overline{\mathrm{Nu}}=\int_{0}^{1} \mathrm{Nu} d x=\frac{1}{N} \sum_{j=1}^{N} N u_{j} .
\end{aligned}
$$

$\overline{\mathrm{Nu}}$ for flow over a cylinder is obtained using Eq. (6):

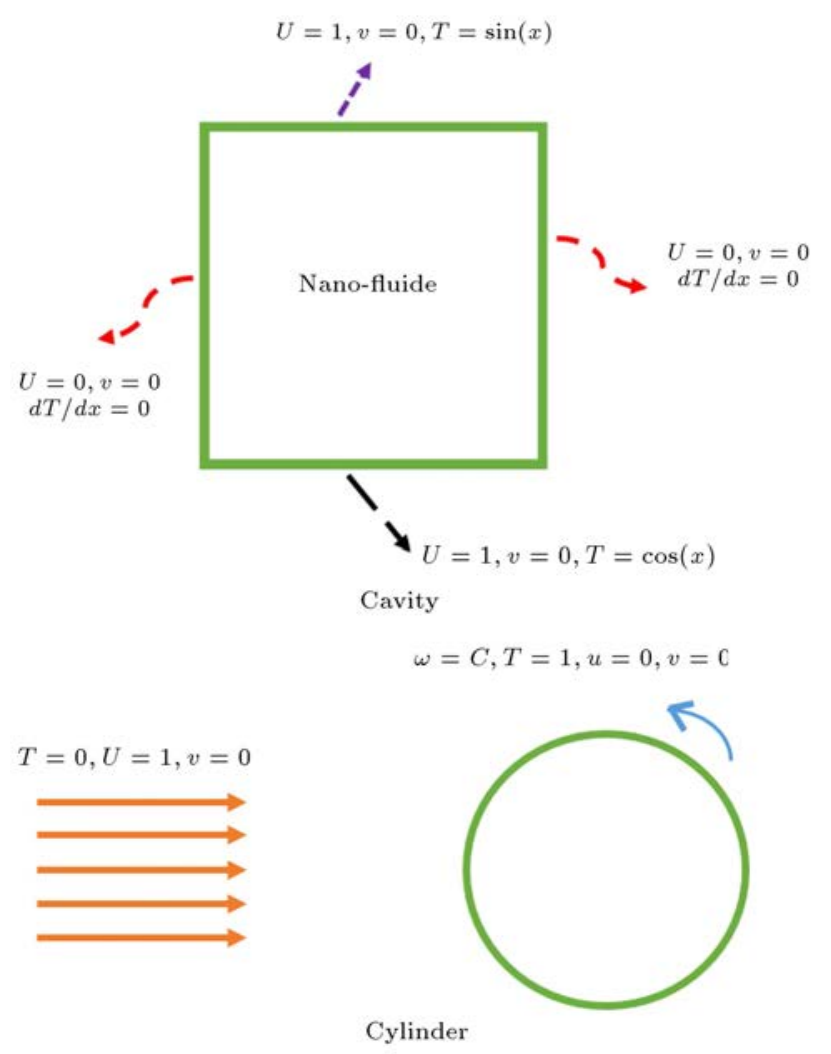

Figure 1. The boundary conditions for cavity flow and flow over a circular cylinder.

$$
\overline{\mathrm{Nu}}=\int_{0}^{2 \pi} \mathrm{Nu} r d \theta=\frac{1}{2 \pi} \sum_{j=1}^{N} \mathrm{Nu}_{j} \Delta \theta
$$

Boundary conditions for flow over the circular cylinder and cavity flows are shown in Figure 1.

\section{Results and discussion}

\subsection{Grid independence and convergence history}

The quadrilateral grids were used in this work. Different grid sizes were selected and simulation was conducted to ensure grid independence. The grid independence check for flow over a cylinder and cavity flow is shown in Figure 2, in which horizontal velocity variations at the vertical centerline of the cavity for different grids are compared. In addition, Nusselt number variations on cylinder wall for different grids are compared in terms of grid independence. The error is calculated below:

$$
\text { Error }=\frac{\sum_{j=1}^{N} \sum_{i=1}^{M}\left(u_{i, j}^{k+1}-u_{i, j}^{k}\right)}{N M} .
$$

The convergence history is obtained and displayed in Figure 3. 

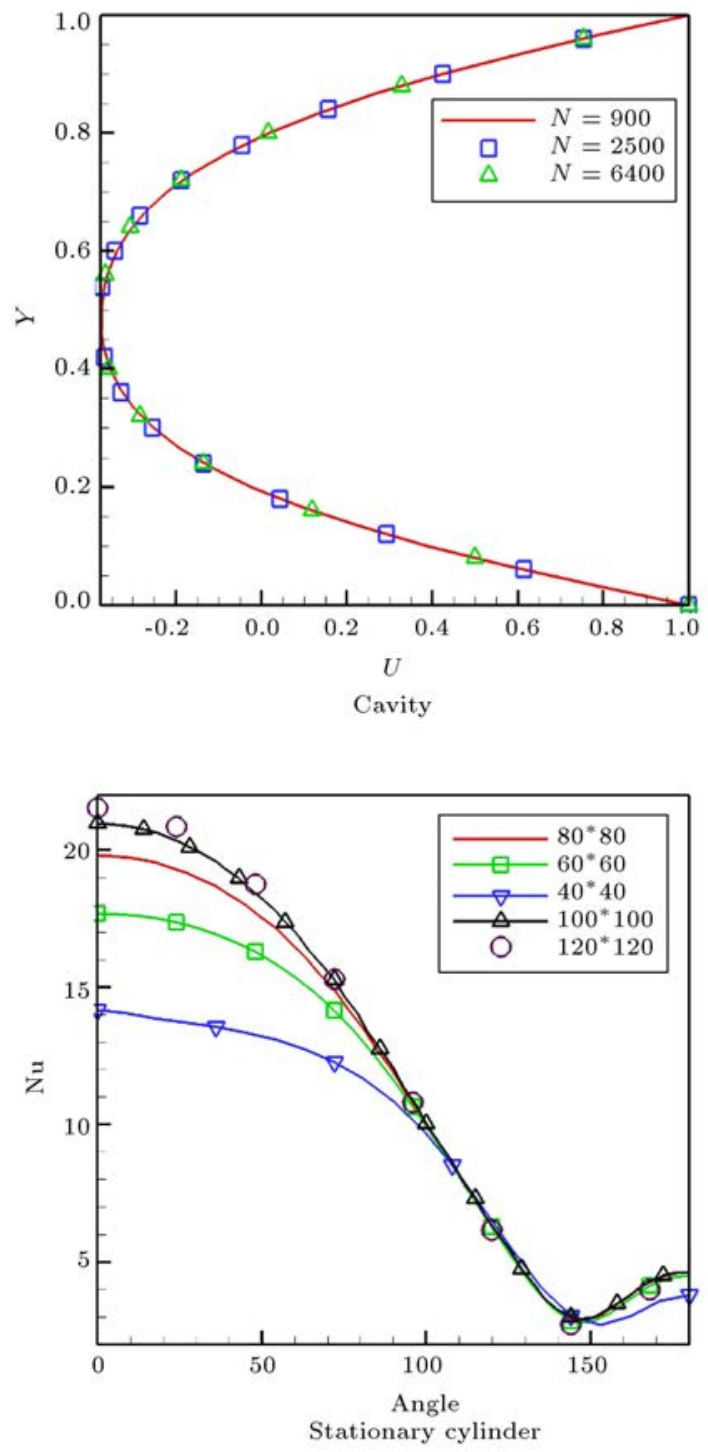

Figure 2. Grid independence for $\mathrm{Al}_{2} \mathrm{O}_{3}$-water nano-fluid at $\mathrm{Ri}=0.2, \operatorname{Re}=20$, and $C=5 \%$.

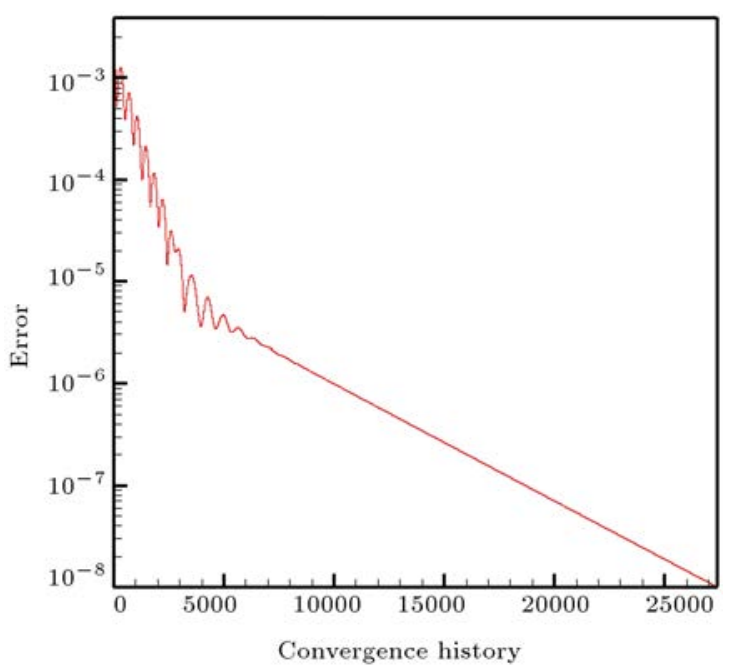

Figure 3. Convergence history of numerical error.
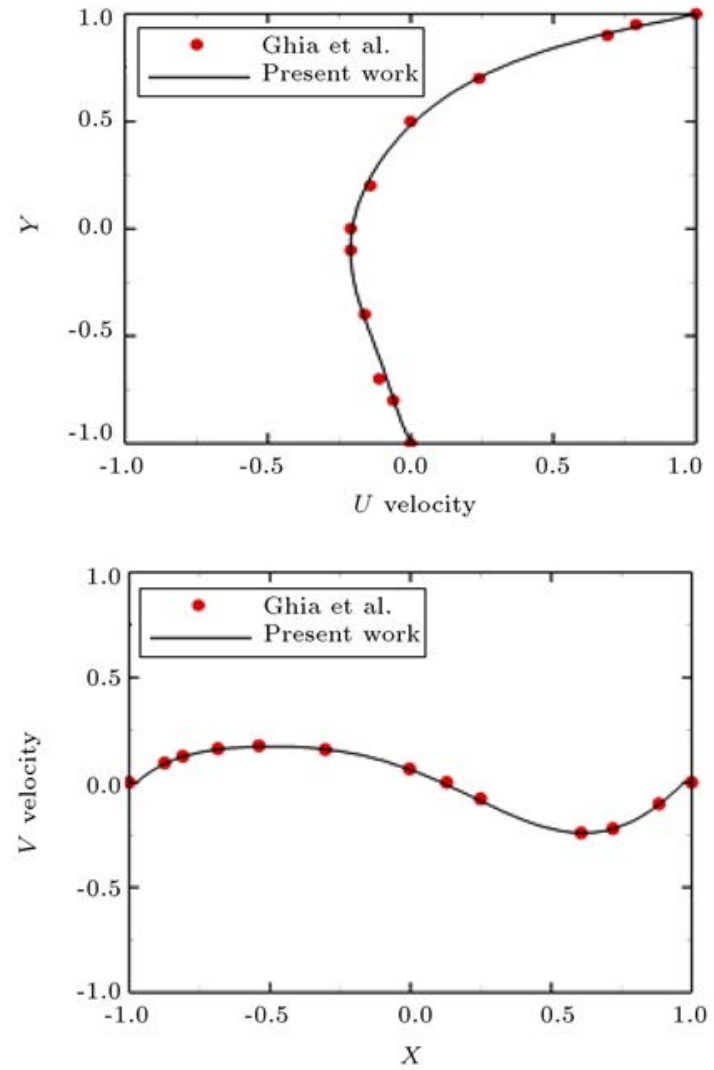

Figure 4. Velocities on the centerlines of the cavity (comparison between our results and those of Ghia et al. [28]).

\subsection{Validation}

For validation, the results of the proposed numerical method for cavity flow are compared with those of Muthtamilselvan et al. [27] in Table 1. The applied boundary conditions are similar to the conditions set by Muthtamilselvan et al. [27] at Ri $=1$. Table 1 shows that the applied novel numerical approach can predict the $\mathrm{Nu}$ number quite accurately in different nano-fluid concentrations. To ensure greater certainty, validation is done through comparisons with the results of Ghia et al. [28]. To this end, the velocities in the $x$ and $y$ directions are obtained on the centerlines of the cavity and are compared with those of Ghia et al. [28] (Figure 4.).

Good agreement is observed, which proves that our new characteristic-based scheme can solve the governing equation numerically with acceptable accuracy.

\subsection{Results of simulation of cavity flow}

The $\mathrm{Al}_{2} \mathrm{O}_{3}$-water nano-fluid flow in a cavity was simulated by the proposed novel numerical approach, and the streamlines at different $\mathrm{Ri}$ numbers are shown in Figure 5. The $\mathrm{Al}_{2} \mathrm{O}_{3}$ concentration in the fluid was assumed to be $5 \%$. At larger Ri numbers, the dominant heat transfer mechanism is natural convection, while at small Ri numbers, the forced convection 
Table 1. Comparison of average Nu numbers for cavity flow obtained by the present numerical approach and that of Muthtamilselvan et al. [27].

\begin{tabular}{lccc}
\cline { 2 - 4 } & \multicolumn{3}{c}{ Average Nu number } \\
\hline Nanoparticles concentration $\%$ & $C=2 \%$ & $C=4 \%$ & $C=6 \%$ \\
Muthtamilselvan et al. [27] & 2.40 & 2.56 & 2.73 \\
Present work & 2.41 & 2.54 & 2.76 \\
\hline
\end{tabular}
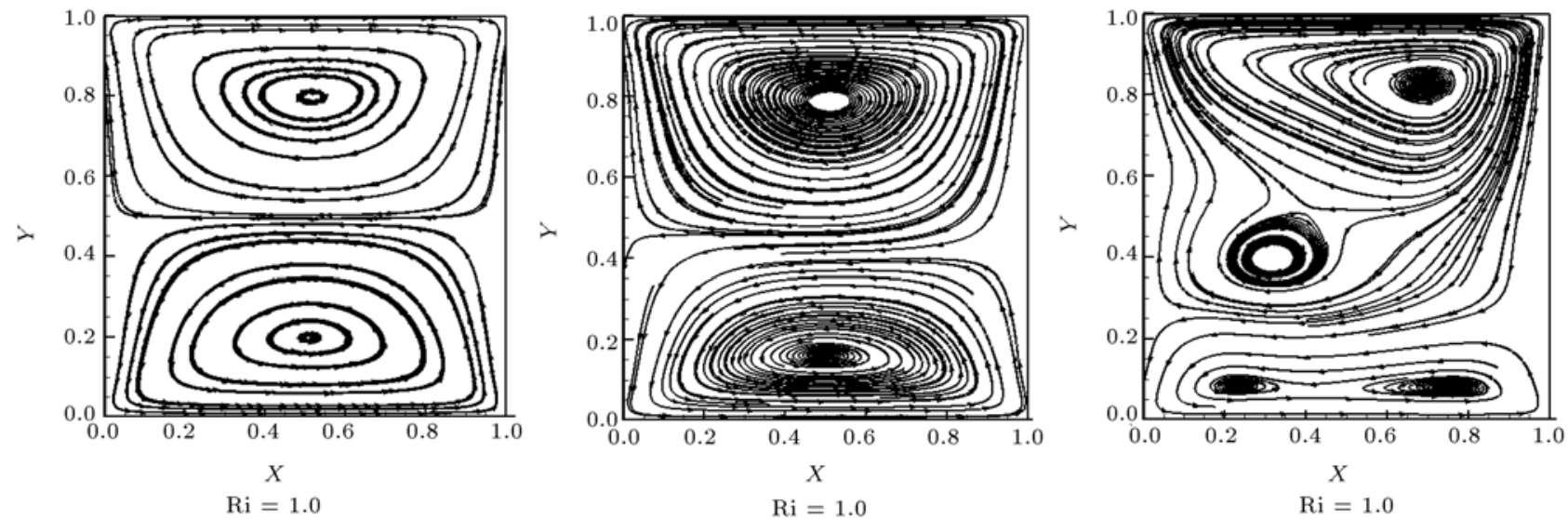

Figure 5. Streamlines at different Richardson numbers for $\mathrm{Al}_{2} \mathrm{O}_{3}$-water nano-fluid at $C=5 \%$.
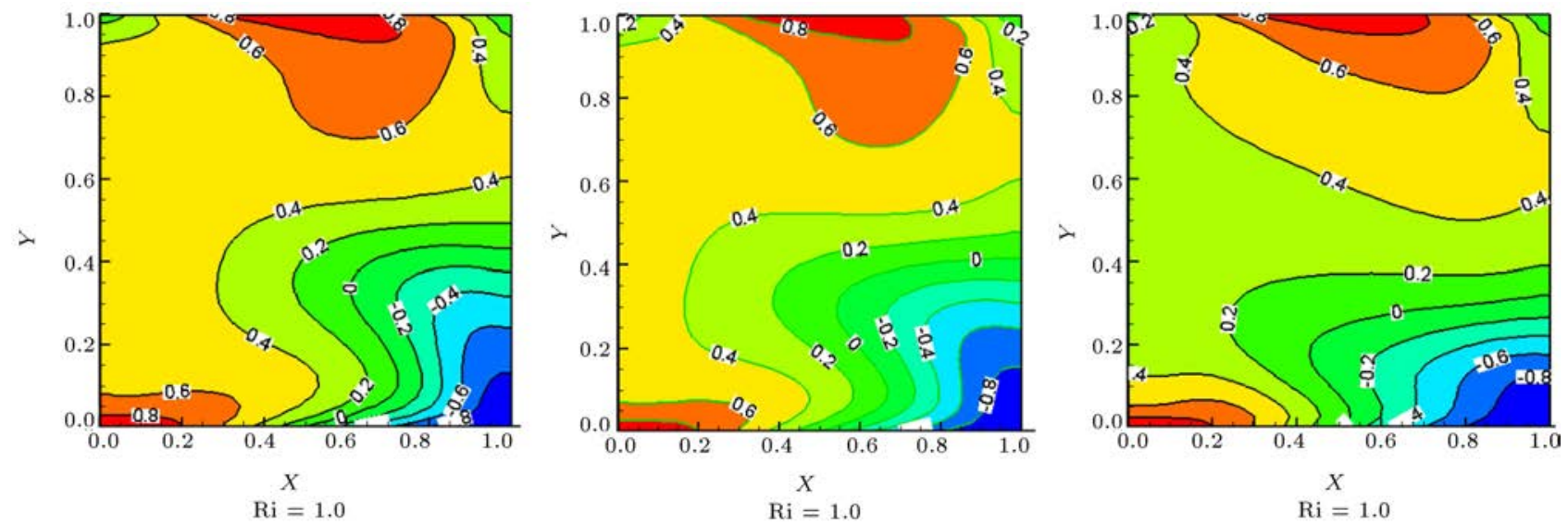

Figure 6. Isotherms at different Richardson numbers for $\mathrm{Al}_{2} \mathrm{O}_{3}$-water nano-fluid at $C=5 \%$ and $\mathrm{Re}=20$.

is the dominant one. At low Richardson numbers, two vortices are produced because of hydrodynamic boundary conditions. Upper and lower walls move to the right and force fluids on the boundary layer to move to the right. Therefore, two almost symmetrical vortices are made in the upper and lower parts. With increase in $\mathrm{Ri}$ number, the natural convection becomes more important, but it is not dominant. Although there are two vortices at medium Richardson numbers the same as small ones, they are not symmetrical anymore. At $\mathrm{Ri}=10$, the natural convection affects the hydrodynamics of the flow and the number of vortices increases. In addition, the formation of four vortices is shown in Figure 5. Due to the effect of the moving upper and lower walls, there are two vortices suppressed to the right wall. Two other ones are the result of the buoyancy effect, which is stronger on the right side because of the higher temperature difference between lower and upper walls. The isotherms at different $\mathrm{Ri}$ numbers for $5 \% \quad \mathrm{Al}_{2} \mathrm{O}_{3}$-water nano-fluid are given in Figure 6, indicating that forced convection remains dominant at small Richardson numbers. The effect of the thermal boundary layer is significant in these cases. The isotherms show that heat penetration from/into both upper and lower walls is high and the value of the isotherms is greater at $\mathrm{Ri}=0.1$ than that at $\mathrm{Ri}=10$. Another important parameter for the cavity flow is AR. The novel developed code was also employed to simulate the cavity flow with $\mathrm{AR}=2$. In this part, the nano-fluid was assumed to be $\mathrm{ZnO}$-water with $C=5 \%$. The streamlines are shown in Figure 7 at different Ri numbers. Figure 7 shows that at $\mathrm{Ri}=$ 

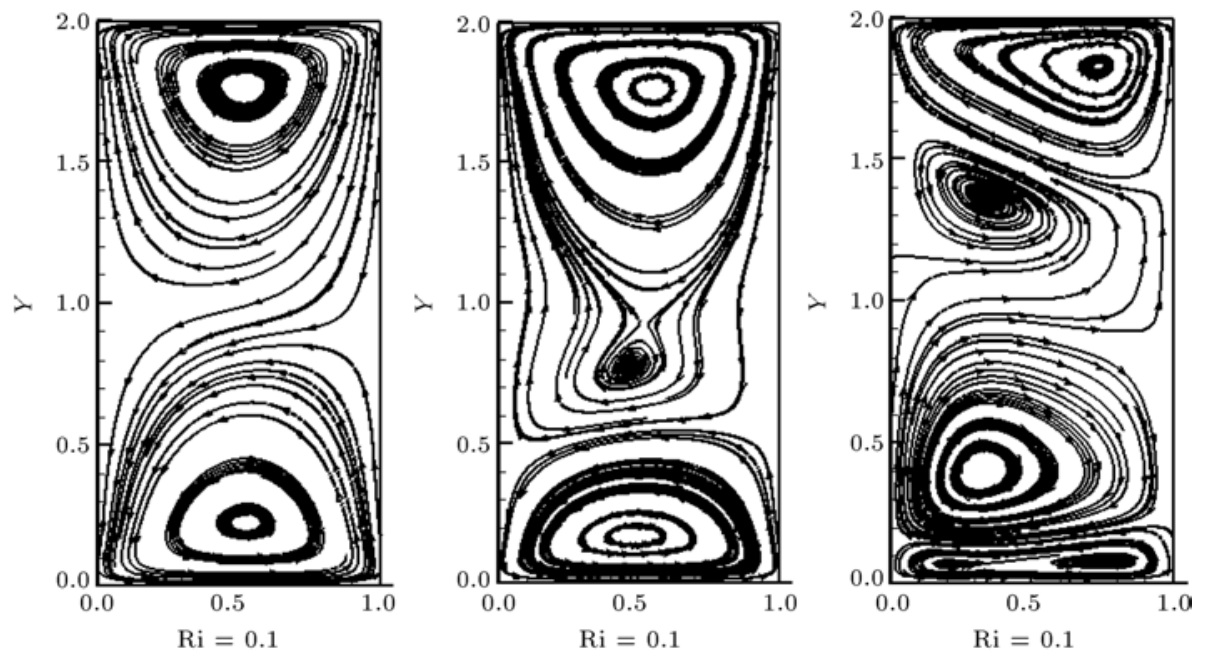

Figure 7. Streamlines for free, mixed, and forced convections ( $\mathrm{ZnO}$-water nano-fluid at $C=5 \%, \mathrm{Re}=20$, and $\mathrm{AR}=2$ ).

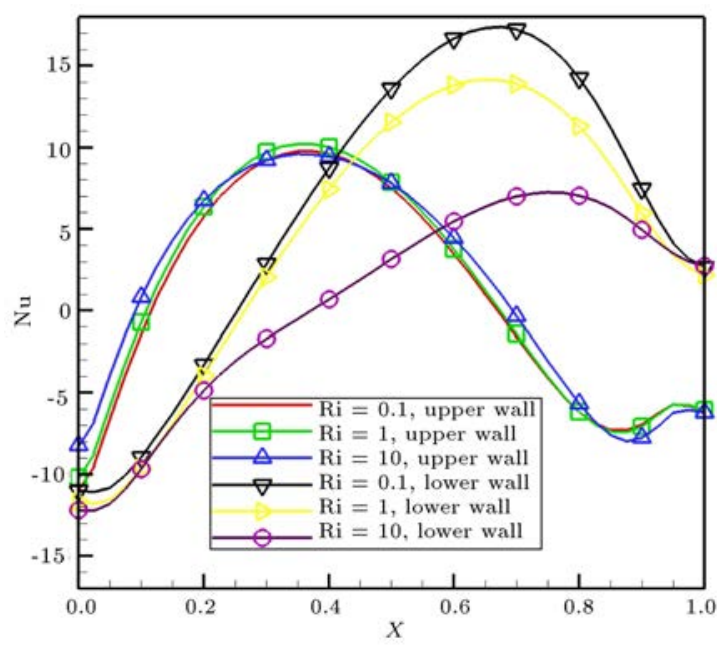

Figure $8 . \mathrm{Nu}$ at upper and lower walls at different $\mathrm{Ri}$ numbers ( $\mathrm{MgO}$-water, $C=5 \%$, and $\mathrm{Re}=20$ ).

0.1 , two almost symmetrical vortices are formed the same as the ones in Figure 5 since natural convection is negligible. At $\mathrm{Ri}=10$, due to the effect of gravity and buoyancy effect, two more vortices are formed, being one more than $\mathrm{AR}=1$. Due to the thermal boundary conditions at the upper and lower walls, the buoyancy effect is more powerful on the right-hand side of the cavity. Therefore, on the top right side of the cavity, the temperature of the upper wall is lower than that of the fluid and the buoyancy effect reinforces the formation of larger vortices in this part. $\mathrm{Nu}$ values for the upper and lower walls of the cavity are compared at different Ri numbers in Figure 8.

$\mathrm{MgO}$-water nano-fluid with $C=5 \%$ is considered as our case-study nano-fluid. The effect of $\mathrm{Ri}$ is negligible on $\mathrm{Nu}$ of the upper wall since the upper wall is warm and the buoyancy cannot influence the flow regime considerably. However, at the lower wall,

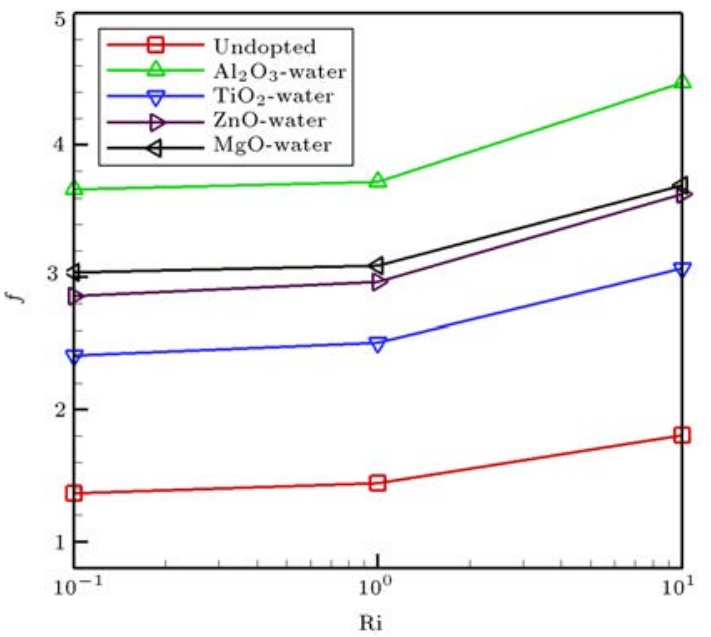

Figure 9. $\bar{f}$ at the upper wall for different nano-fluids at Re $=20$ and $C=5 \%$.

the temperature gradient results in higher buoyancy effect and $\mathrm{Nu}$ increases when the Richardson number decreases. There are some extremums in the $\mathrm{Nu}-$ $\mathrm{X}$ chart since hydrodynamic and thermal boundary conditions are very complicated and periodic. Effects of different nano-fluids and Ri number on the average friction factor $(\bar{f})$ at the upper and lower walls are shown in Figures 9 and 10, respectively. $\mathrm{Al}_{2} \mathrm{O}_{3}$-water and $\mathrm{TiO}_{2}$-water nano-fluids have maximum and minimum $\bar{f}$ values for upper and lower walls, respectively, because the relative viscosities of the $\mathrm{Al}_{2} \mathrm{O}_{3}$-water and the $\mathrm{TiO}_{2}$-water are maximum and minimum, respectively. $\bar{f}$ is minus for the lower wall because it moves to the right. As a result, shear stress and $\bar{f}$ are minus in the lower wall. Of note, the value of the average friction factor at the lower wall increases when the Richardson number decreases. However, at the upper wall, increase in $\mathrm{Ri}$ numbers elevates the average friction factor. It 


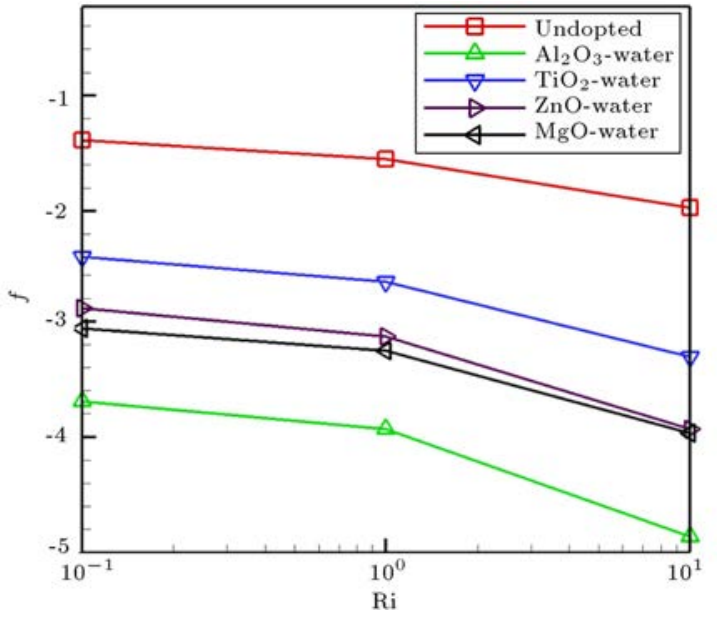

Figure 10. $\bar{f}$ at the lower wall for different nano-fluids at $\mathrm{Re}=20$ and $C=5 \%$.

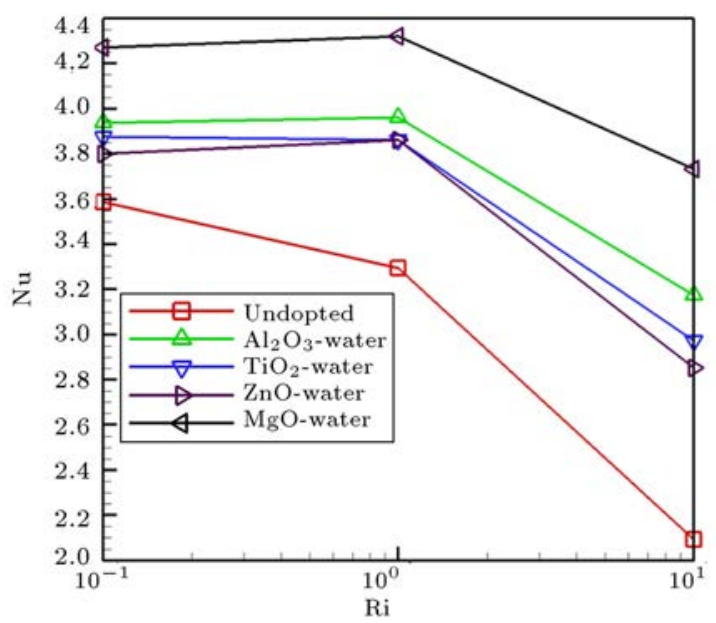

Figure 11. $\overline{\mathrm{Nu}}$ at the upper wall number for different nano-fluids at $\operatorname{Re}=20$ and $C=5 \%$.

is the result of the temperature boundary condition on the lower and upper walls. As mentioned previously, the hot upper wall cannot considerably influence the hydrodynamics of flow, while for the lower wall, it is completely an effective parameter in the boundary layer formation. The buoyancy tends to separate the fluid from the lower wall; therefore, at larger Ri numbers, when the natural convection is dominant, the average friction factor decreases. Average $\mathrm{Nu}$ values for different nano-fluids at the upper and lower walls versus $\mathrm{Ri}$ are demonstrated in Figures 11 and 12, respectively. The $\mathrm{MgO}$-water and $\mathrm{ZnO}$-water nano-

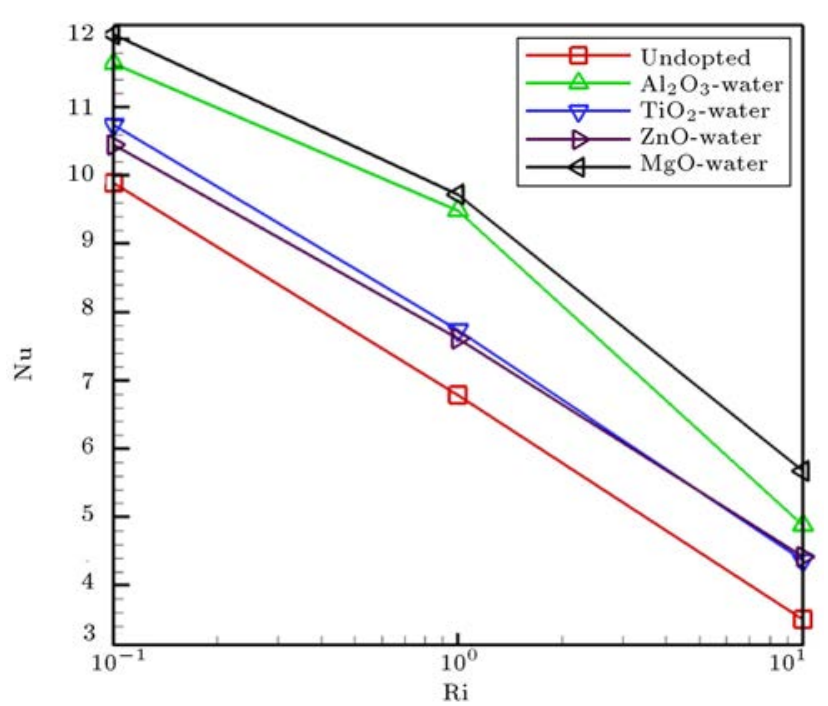

Figure 12. $\overline{\mathrm{Nu}}$ at the lower wall for different nano-fluids at $\operatorname{Re}=20$ and $C=5 \%$.

fluids have maximum and minimum $\overline{\mathrm{Nu}}$ values for the upper and lower walls, respectively, which can be attributed to the higher thermal conductivity of these nano-fluids. $\overline{\mathrm{Nu}}$ decreases when the Richardson number increases in all cases, since natural convection indicates lower heat transfer than forced convection. Since the effect of natural convection on the upper wall is not as much as that on the lower wall, for mixed and forced convections $(\mathrm{Ri}=0.1$ and 1$)$, the $\mathrm{Nu}$ at the upper wall remains almost unchanged. The effect of AR on the average $\mathrm{Nu}$ and friction factor of the cavity flow is shown in Table 2. The nano-fluid was assumed $\mathrm{MgO}-$ water with $C=5 \%$ and the $\mathrm{Ri}$ was 0.1 . In this case, forced convection is dominant and the moving walls cannot move the fluid at the center of the cavity easily when the AR increases. Therefore, both $\overline{\mathrm{Nu}}$ and $\bar{f}$ decrease when the AR increases.

\subsection{Results of simulation of flow over a cylinder}

In this section, flow over stationary and rotating cylinders is simulated. $\mathrm{Al}_{2} \mathrm{O}_{3}, \mathrm{TiO}_{2}, \mathrm{MgO}$, and $\mathrm{ZnO}$ are used as ceramic dopants in water. Streamlines and isotherms point to the flows over stationary and rotating cylinders in Figures 13 and 14, respectively. $\mathrm{MgO}$-water with $C=5 \%$ is considered as a nanofluid in this case. Streamlines and isotherms are symmetrical in terms of the stationary cylinder. No vortex is observed for forced convection flow over the

Table 2. The $\bar{f}$ and the $\overline{\mathrm{Nu}}$ for $\mathrm{MgO}$-water nano-fluid at $C=5 \%, \mathrm{Re}=20$, and $\mathrm{Ri}=0.1$.

\begin{tabular}{cccccc}
\hline \multirow{W}{W}{$\boldsymbol{L} \boldsymbol{L}$ ratio } & \multicolumn{3}{c}{$\overline{\mathrm{Nu}}$} & & \multicolumn{2}{c}{$\overline{\boldsymbol{f}}$} \\
\cline { 2 - 3 } \cline { 5 - 6 } & Upper wall & Lower wall & & Upper wall & Lower wall \\
\hline 0.5 & 5.423 & 12.668 & & 4.398 & -4.404 \\
1.0 & 4.270 & 12.061 & & 3.035 & -3.061 \\
2.0 & 3.582 & 10.666 & & 2.258 & -2.282 \\
4.0 & 2.659 & 8.128 & & 1.589 & -1.606 \\
\hline
\end{tabular}



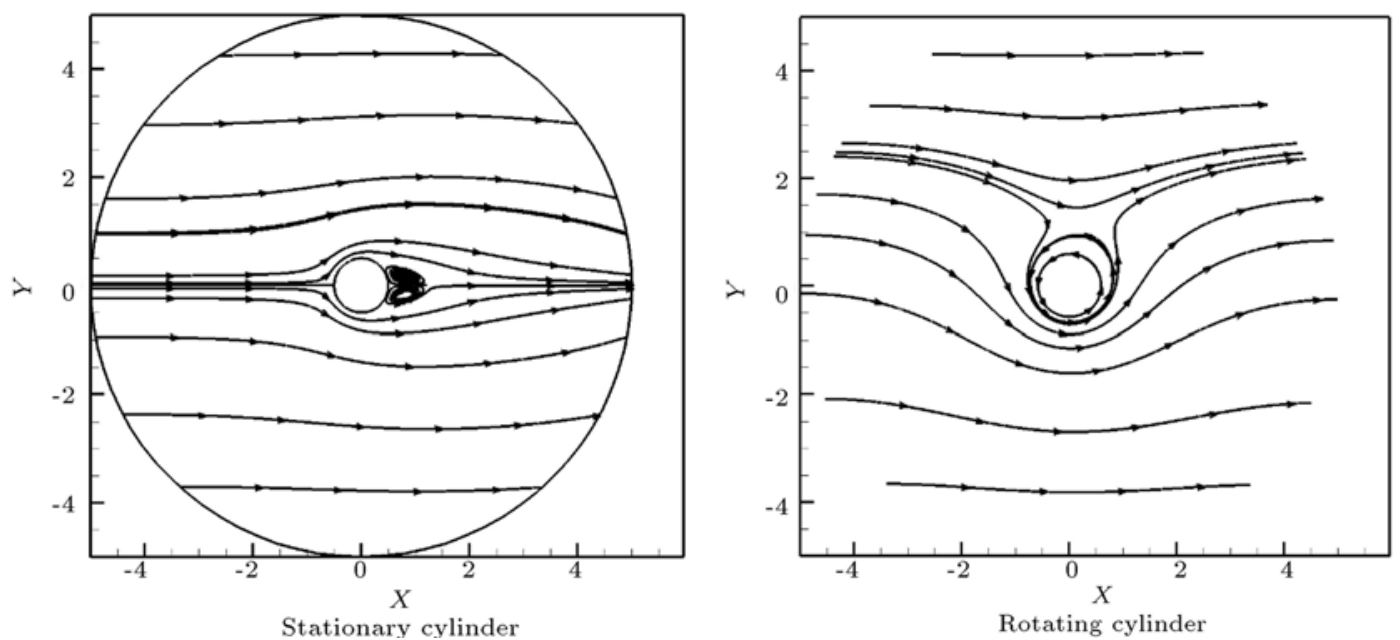

Figure 13. Streamlines of flow over stationary and rotating cylinders ( $\mathrm{MgO}$-water nano-fluid, $\mathrm{Ri}=0, C=5 \%$, and $\mathrm{Re}=$ 20).
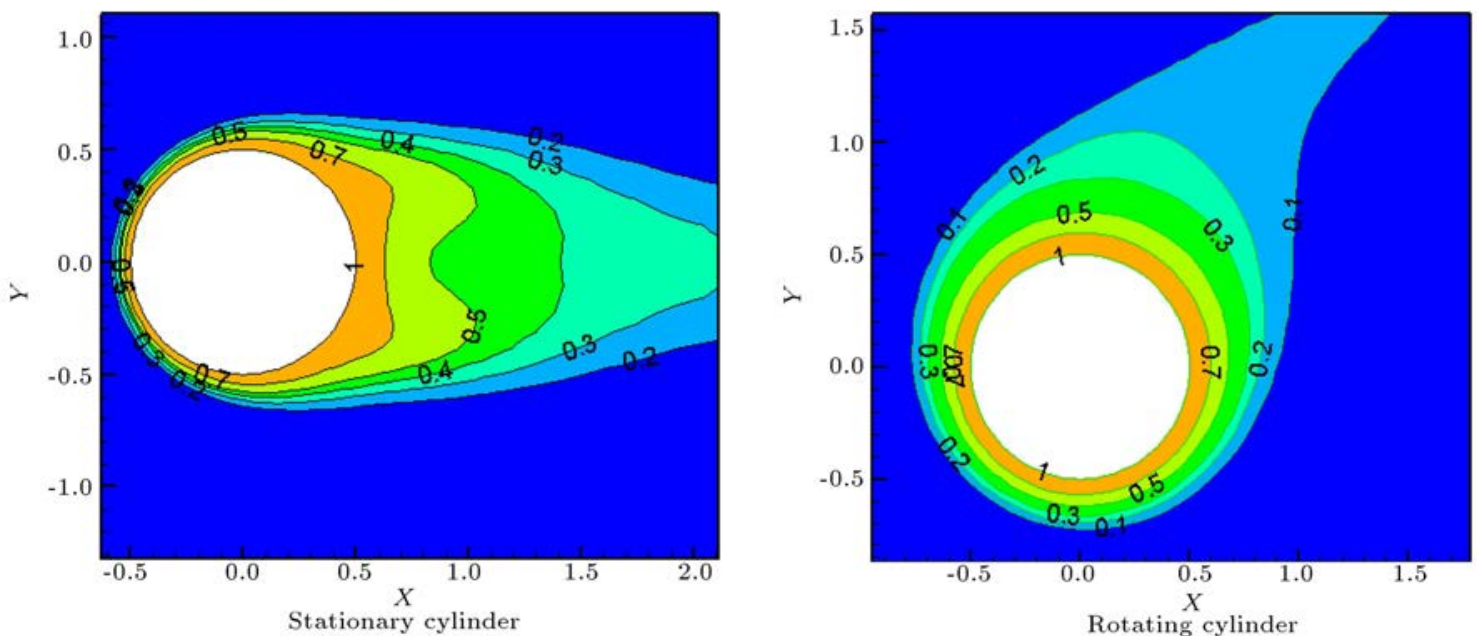

Figure 14. Isotherms for flow over stationary and rotating cylinders ( $\mathrm{MgO}$-water nano-fluid, $\mathrm{Ri}=0, C=5 \%$, and $\mathrm{Re}=$ $20)$.
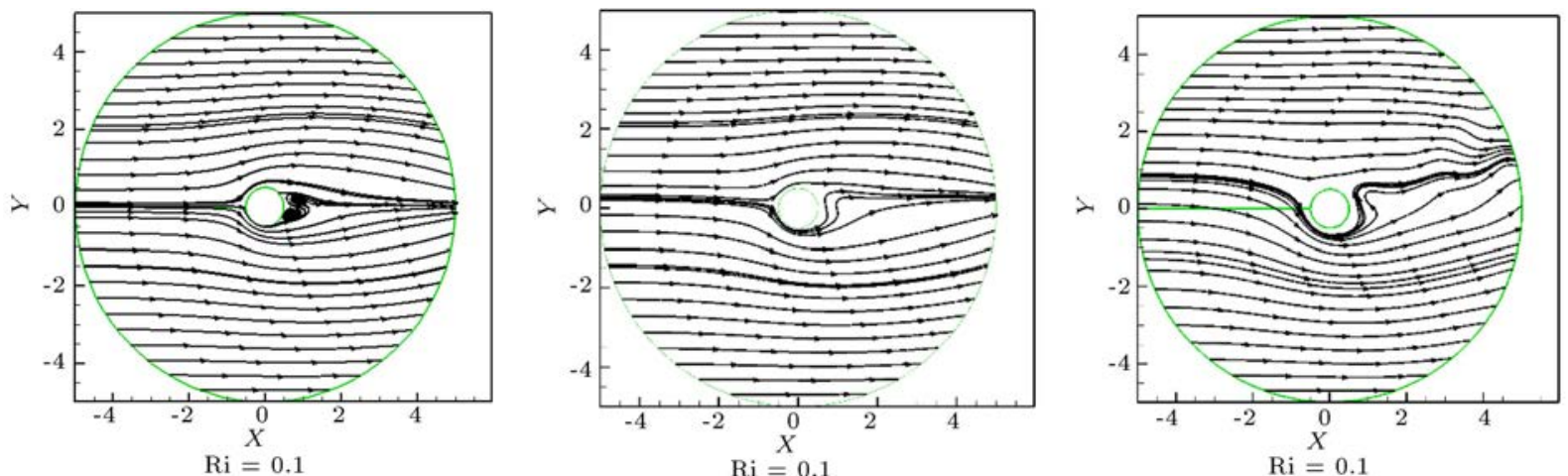

Figure 15. Comparison of streamlines at different Richardson numbers in stationary cylinder (ZnO-water nano-fluid, Ri $=0, C=5 \%)$.

rotating cylinder. Angular velocity of cylinder forces fluid near the cylinder to rotate around the center of the cylinder. Therefore, the vortices disappear around the rotating cylinder, compared to the stationary one. However, it should be noted that despite the stationary cylinder, the lift force acts on the rotating one due to the asymmetric pressure distribution. Streamlines and isotherms are compared for different kinds of convections in flow over the stationary cylinder in Figures 15 and 16, respectively. ZnO-water nano- 

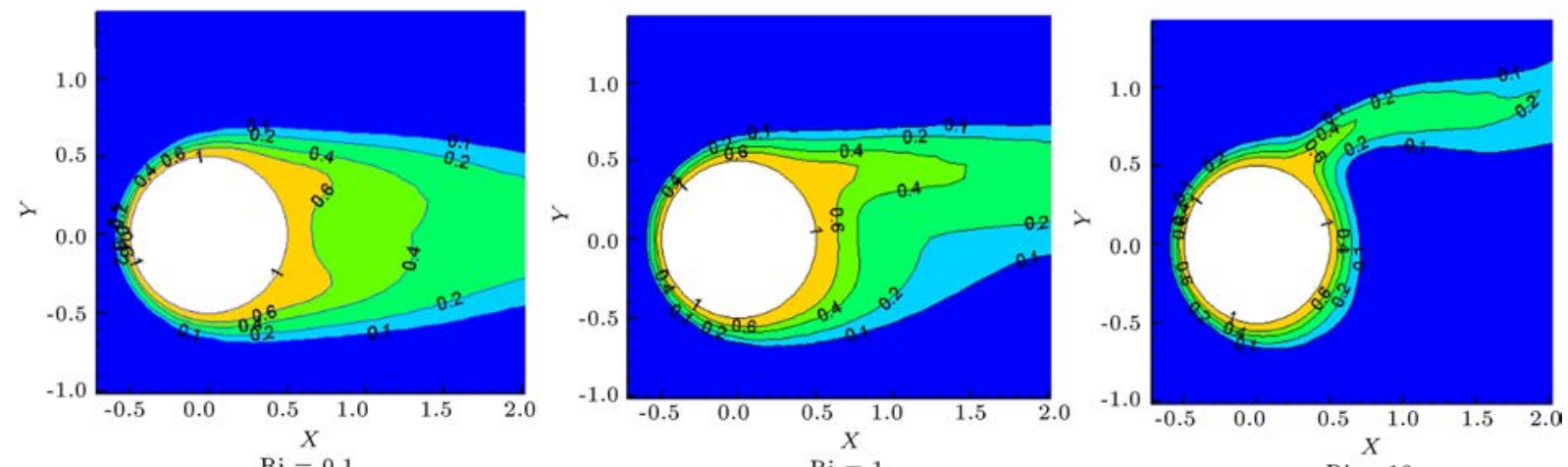

Figure 16. Comparison of isotherms at different Richardson numbers in the stationary cylinder (ZnO-water nano-fluid, Ri $=0$, and $C=5 \%$ ).

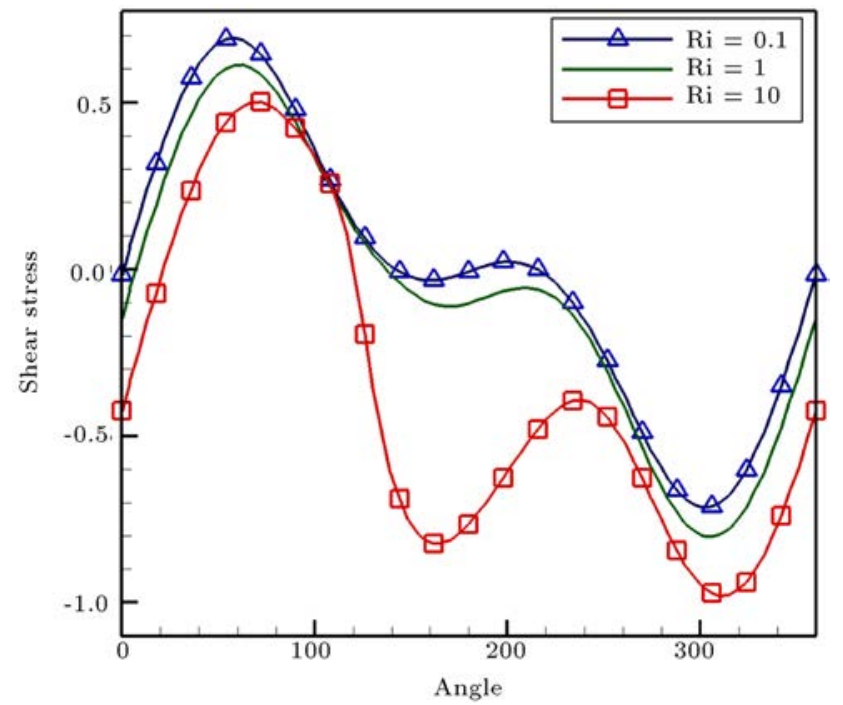

Figure 17. Comparison between shear stress at different Richardson numbers in the stationary cylinder ( $\mathrm{TiO}_{2}$-water nano-fluid and $\mathrm{C}=5 \%$ ).

fluid with $C=5 \%$ is used in this simulation. Free convection destroys the vortices at medium and large Richardson numbers since free convection is dominant in such cases. Forced convection is dominant at smaller Richardson numbers and forces the fluid downwards. Fluid conveys heat from cylinders downwards. As a result, the temperature of the downward fluid is higher at smaller Ri. Shear stress and pressure coefficient are compared at different $\mathrm{Ri}$ values for flow over the stationary cylinder in Figures 17 and 18, respectively. $\mathrm{TiO}_{2}$-water with $C=5 \%$ is considered as a nano-fluid in this simulation. Shear stress and pressure coefficient are almost symmetrical at smaller Richardson numbers because free convection is negligible in this state. Shear stress is high at the angles between $0^{\circ}$ and $90^{\circ}$. The pressure coefficient is usually high at the station point $\left(0^{\circ}\right)$. Nusselt numbers are compared at different Richardson numbers for flow over the rotating cylinder, as shown in Figure 19. $\mathrm{Al}_{2} \mathrm{O}_{3}$-water with $C=5 \%$ is considered to be the nano-fluid in this case.

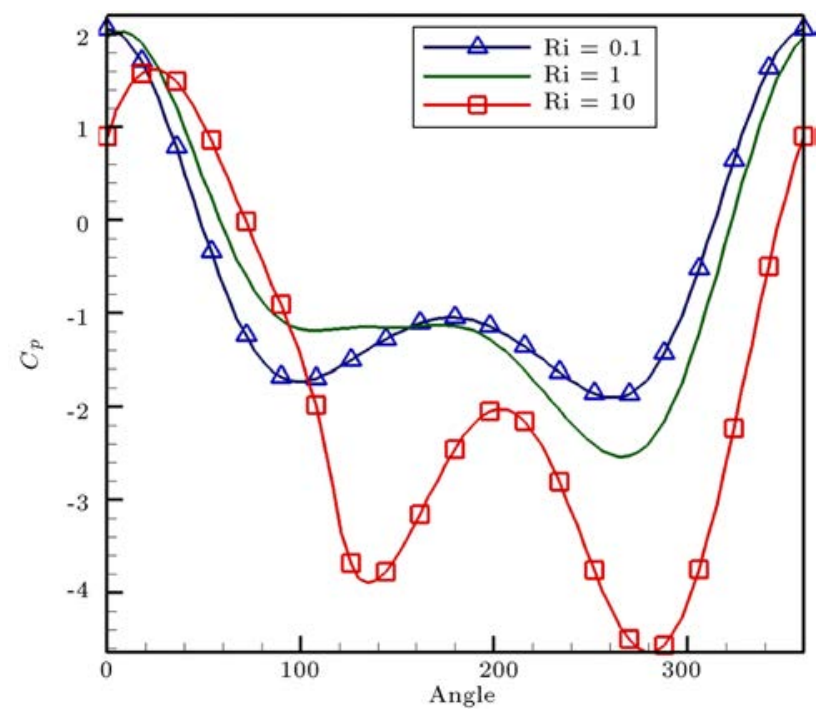

Figure 18. Comparison of pressure coefficient at different Richardson numbers in the stationary cylinder $\left(\mathrm{TiO}_{2}\right.$-water nano-fluid and $\left.C=5 \%\right)$.

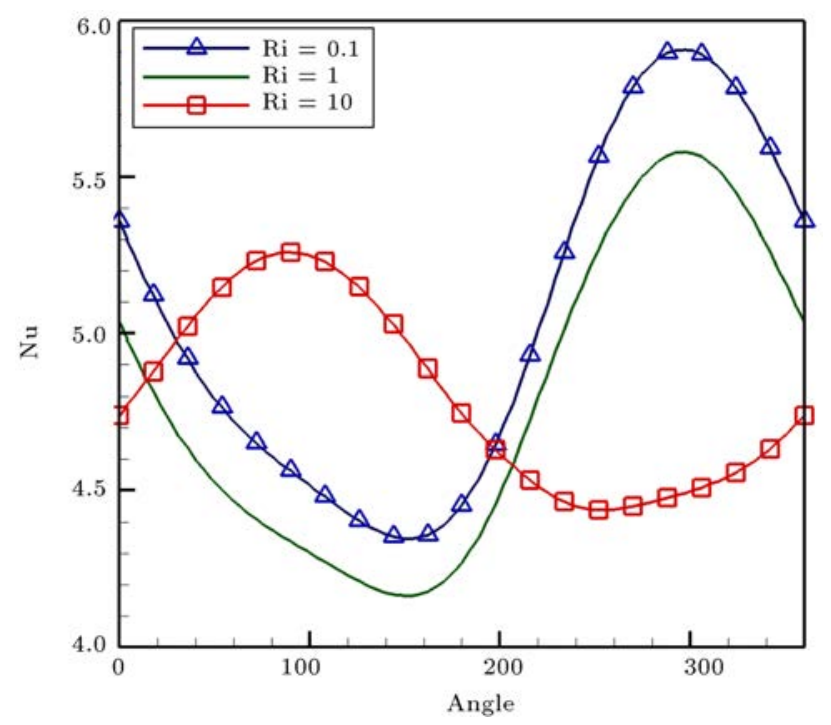

Figure 19. Comparison of $\mathrm{Nu}$ at different $\mathrm{Ri}$ values in the rotating cylinder $\left(\mathrm{Al}_{2} \mathrm{O}_{3}\right.$-water nano-fluid, $C=5 \%$, and $w=10$ ). 


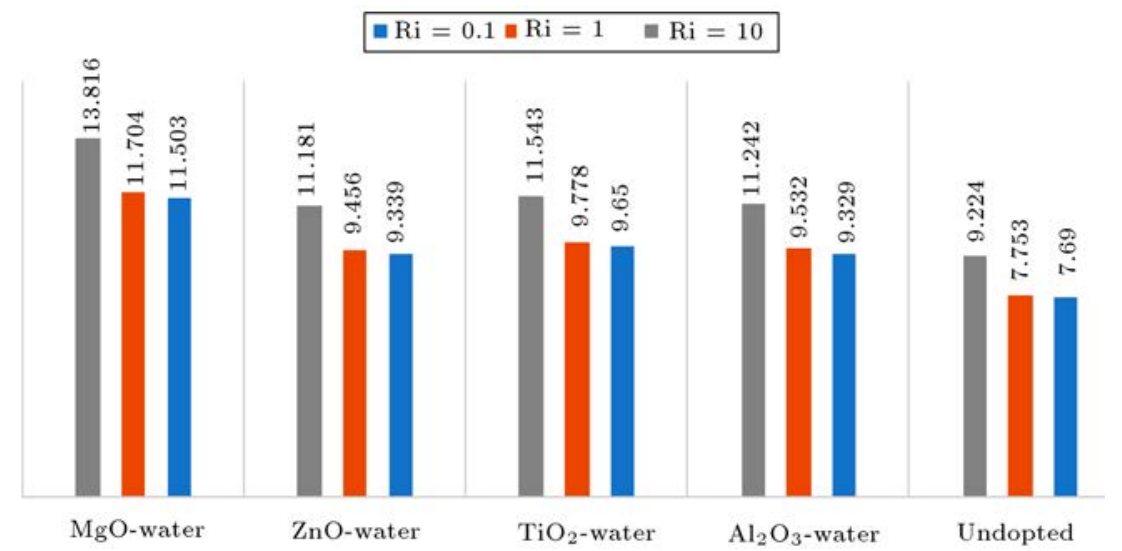

Figure 20. $\overline{\mathrm{Nu}}$ for the stationary cylinders for different Richardson numbers and nano-fluids at $\operatorname{Re}=20$ and $C=5 \%$.

Combination between the mixed convection and the effect of cylinder rotation results in complex Nusselt number variation. Nusselt number is maximum at the lower part of the cylinder at smaller and medium Richardson numbers and is minimum at the upper part of the cylinder at larger Richardson numbers. The $\overline{\mathrm{Nu}}$, calculated for four selected nano-fluids and pure water, is compared at different Richardson numbers in Figure 20. $\mathrm{MgO}$-water has maximum $\overline{\mathrm{Nu}}$ between selected nano-fluids at all Richardson numbers. $\mathrm{Al}_{2} \mathrm{O}_{3}$ water has minimum $\overline{\mathrm{Nu}}$ at small Richardson numbers, and $\mathrm{ZnO}$-water has minimum $\overline{\mathrm{Nu}}$ at medium and large Richardson numbers.

\section{Conclusions}

Different models of heat convections were simulated in this work. The case studies were cavity flow and flow over stationary and rotating cylinders. Results demonstrated that when Richardson number increased, the number of vortices increased in cavity flow, but vortices vanished for flow over a stationary cylinder. Also, when Richardson number increased, $\bar{f}$ increased and $\overline{\mathrm{Nu}}$ decreased in cavity flow. $\bar{f}$ and $\overline{\mathrm{Nu}}$ decreased when the aspect ratio of cavity increased. Comparisons between different nano-fluids demonstrated maximum and minimum $\overline{\mathrm{Nu}}$ values for $\mathrm{MgO}$-water and $\mathrm{ZnO}$ water, respectively, for flow over the rotating cylinder. When rotational speed increased, $\overline{\mathrm{Nu}}$ and Nusselt number variations decreased on the cylinder wall.

\section{Nomenclature}

$\begin{array}{ll}A & \text { Area } \\ \text { AR } & \text { Aspect Ratio } \\ C & \text { The volume fraction of nanoparticle } \\ C_{p} & \text { Specific heat in constant pressure } \\ & (\mathrm{J} / \mathrm{kg} / \mathrm{K}) \\ D & \text { Diameter }(\mathrm{m})\end{array}$

$\begin{array}{ll}F & \text { Friction factor } \\ \bar{f} & \text { Mean friction factor } \\ \mathrm{Gr} & \text { Grashof number } \\ K & \text { Thermal conductivity }(\mathrm{W} / \mathrm{m} / \mathrm{K}) \\ M & \text { Number of cells in } x \text {-direction } \\ N & \text { Number of cells in } y \text {-direction } \\ N c & \text { Thermal conductivity parameter } \\ \mathrm{Nu} & \text { Local Nusselt number } \\ \mathrm{Nu} & \text { Mean Nusselt number } \\ N v & \text { Dynamic viscous parameter } \\ P & \text { Pressure } \\ \mathrm{Re} & \text { Reynolds number } \\ \mathrm{Ri} & \text { Richardson } \\ T & \text { Temperature } \\ \mathrm{Pr} & \text { Prandtl number } \\ u, v & x, y \text { velocity components } \\ t & \text { Time } \\ U, v & \text { Velocities } \\ x, y, r & \text { Coordinates }\end{array}$

\section{Greek symbols}

$\beta \quad$ Thermal expansion coefficient $\left(\mathrm{K}^{-1}\right)$

$\mu \quad$ Coefficient of viscosity $(\mathrm{kg} / \mathrm{m} / \mathrm{s})$

$\omega \quad$ Rotational speed

$\nu \quad$ Kinematic viscosity $\left(\mathrm{m}^{2} / \mathrm{s}\right)$

$\rho \quad$ Density $\left(\mathrm{kg} / \mathrm{m}^{3}\right)$

$\tau \quad$ Shear stress

$\in \quad$ Artificial compressibility

\section{Subscripts}

$\begin{array}{ll}\text { ref } & \text { Reference } \\ b f & \text { Body fluid } \\ n f & \text { Nano-fluid } \\ p & \text { Particle }\end{array}$




\section{References}

1. Webb, R.L. and Kim, N.H., Principles of Enhanced Heat Transfer, CRC Press (2007)

2. Moghanlou, F., Shams Khorrami, A., Esmaeilzadeh, E., et al. "Experimental study on electrohydrodynamically induced heat transfer enhancement in a minichannel", Exp. Therm. Fluid Sci., 59, pp. 24-31 (2014).

3. Adibi, T., Razavi, S.E., and Adibi, O. "A characteristic-based numerical simulation of watertitanium dioxide nano-fluid in closed domains", Int. J. Eng. Technol., 33(1), pp. 158-163 (2020).

4. Sakkaki, M., Moghanlou, F., Parvizi, S., et al. "Phase change materials as quenching media for heat treatment of 42CrMo4 steels", J. Cent. South Univ., 27, pp. $752-761$ (2020).

5. Maïga, S.E.B., Palm, S.J., Nguyen, C.T., et al. "Heat transfer enhancement by using nanofluids in forced convection flows", INT. J. HEAT FLUID FL., 26(4), pp. 530-546 (2005).

6. Kefayati, G.R. "Lattice Boltzmann simulation of natural convection in nanofluid-filled 2D long enclosures at presence of magnetic field", Theor. Comput. Fluid Dyn., 27(6), pp. 865-883 (2013).

7. Mahmoodi, M. "Numerical simulation of free convection of nanofluid in a square cavity with an inside heater", Int. J. Therm. Sci., 50(11), pp. 2161-2175 (2011).

8. Rahmati, A.R. and Tahery, A.A. "Numerical study of nanofluid natural convection in a square cavity with a hot obstacle using lattice Boltzmann method", Alex. Eng. J., 57(3), pp. 1271-1286 (2018).

9. Akbarinia, A. and Behzadmehr, A. "Numerical study of laminar mixed convection of a nanofluid in horizontal curved tubes", Appl. Therm. Eng., 27(8), pp. 1327-1337 (2007).

10. Heydari, A., Shateri, M., and Sanjari, S. "Numerical analysis of a small size baffled shell-and-tube heat exchanger using different nano-fluids", Heat Transf. Eng., 39(2), pp. 141-153 (2018).

11. Uysal, C., Arslan, K., and Kurt, H. "A numerical analysis of fluid flow and heat transfer characteristics of $\mathrm{ZnO}$-ethylene glycol nanofluid in rectangular microchannels", Stroj. Vestn-J. Mech. Eng., 62(10), p. 11 (2016).

12. Sunil, A.K. and Kumar, R. "LBM analysis of microconvection in MHD nanofluid flow", Stroj. Vestn-J. Mech. Eng., 63(7-8), p. 13 (2017).

13. Al-Kouz, W.G., Kiwan, S., Alkhalidi, A., et al. "Numerical study of heat transfer enhancement for low-pressure flows in a square cavity with two fins attached to the hot wall using $\mathrm{Al}_{2} \mathrm{O}_{3}$-air nanofluid", Stroj. Vestn-J. Mech. Eng., 64(1), p. 11 (2018).
14. Zhang, W., Hosseini Taleghani, A., Ayani, M., et al. "Nanoparticle and shape factor for improving solidification rate", Int. J. Mod. Phys. C., 31(10), p. 2050141 (2020).

15. Farooq, M., Salahuddin, A., Razzaq, M., et al. "Computational analysis for unsteady and steady magnetohydrodynamic radiating nano fluid flow past a slippery stretching sheet immersed in a permeable medium", Sci. Iran., 27(6), pp. 3454-3466 (2020).

16. Sravanthi, C.S. "Slip flow of nano fluid over a stretching vertical cylinder in the presence of non-linear thermal radiation and non-uniform heat source/sink", Sci. Iran., 25(4), pp. 2098-2110 (2018).

17. Ghaffarpasand, O. and Fazeli, D. "Numerical analysis of MHD mixed convection flow in a parallelogramic porous enclosure filled with nano fluid and in presence of magnetic field induction", Sci. Iran., 25(3), pp. 1789-1807 (2018).

18. Nawaz, M. "Numerical study of hydrothermal characteristics in nano fluid using KKL model with Brownian motion", Sci. Iran., 26(3), pp. 1931-1943 (2019).

19. Adibi, T. "Three-dimensional characteristic approach for incompressible thermo-flows and influence of artificial compressibility parameter", Journal of Computational \& Applied Research in Mechanical Engineering (JCARME), 8(2), pp. 223-234 (2019).

20. Adibi, T. and Razavi, S.E. "A new characteristic approach for incompressible thermo-flow in Cartesian and non-Cartesian grids", Int. J. Numer. Methods Fluids, 79(8), pp. 371-393 (2015).

21. Razavi, S.E. and Adibi, T. "A novel multidimensional characteristic modeling of incompressible convective heat transfer", J Appl Fluid Mech, 9(4), pp. 283-296 (2016).

22. Chorin, A.J. "A numerical method for solving incompressible viscous flow problems", J. Comput. Phys., 135(2), pp. 118-125 (1997).

23. Sabour, M., Ghalambaz, M., and Chamkha, A. "Natural convection of nanofluids in a cavity: criteria for enhancement of nanofluids", Int. J. Numer. Method H., 27(7), pp. 1504-1534 (2017).

24. Borgnakke, C. and Sonntag, R.E., Fundamentals of Thermodynamics, John Wiley \& Sons (2015).

25. Adibi, T., Adibi, O., and Razavi, S.E. "A characteristic-based solution of forced and free convection in closed domains with emphasis on various fluids", Int. J. Eng. Technol., 32(11), pp. 1689-1695 (2019).

26. Adibi, T. and Adibi, O. "Laminar forced convection simulation at different boundary conditions with averaging scheme (numerical and theoretical research", Math. Model. Eng. Probl, 6(4), pp. 519-526 (2019).

27. Muthtamilselvan, M., Kandaswamy, P., and Lee, J. "Heat transfer enhancement of copper-water nanoflu- 
ids in a lid-driven enclosure", Comm. Nonlinear Sci. Numer. Simulat., 15(6), pp. 1501-1510 (2010).

28. Ghia, U., Ghia, K.N., and Shin, C.T. "High-Re solutions for incompressible flow using the Navier-Stokes equations and a multigrid method", J. Comput. Phys., 48(3), pp. 387-411 (1982).

\section{Biographies}

Tohid Adibi is currently an Assistant Professor at the University of Bonab. He graduated in Mechanical Engineering in $\mathrm{BSc}, \mathrm{MSc}$, and $\mathrm{PhD}$ from the Iran University Science and Technology, Sharif University of Technology, Tehran, Iran and the University of Tabriz, Tabriz, Iran, respectively. His research interests include computational fluid dynamics, HVAC, and heat transfer. He has published several conference and journal papers in the field of CFD, combustion, HVAC, and heat transfer.

Seyed Esmail Razavi currently is a Professor at the School of Mechanical Engineering at the University of Tabriz, Tabriz, Iran. He graduated from MSc and PhD from McGill University, Canada. His research interests include computational fluid dynamics and biomedical engineering. Also, he served as the Editor-in-Chief of the Journal of Mechanical Engineering since 2014 up to 2019 .

Omid Adibi currently is an Assistant Professor at the Niroo Research Institute, Tehran, Iran. He did his MSc and PhD in Mechanical Engineering at the Sharif University of Technology, Tehran, Iran. He has published several conference and journal papers in the field of CFD, combustion, HVAC, and heat transfer.

Mohammad Vajdi currently works at the Department of Mechanical Engineering, University of Mohaghegh Ardabili, Ardabil, Iran. Mohammad does research in Mechanical Engineering. His research interests include fluid dynamics and heat transfer in microsystems and bio-fluidics. He also has performed a series of experimental and numerical studies about turbo-machinery.

Farhad Sadegh Mighanlou currently works at the Department of Mechanical Engineering, University of Mohaghegh Ardabili, Ardabil, Iran. His research interests include fluid dynamics and heat transfer in microsystems and bio-fluidics. He also has performed a series of experimental and numerical studies about ultra-high temperature ceramics. 